\title{
O Controle Social no Conselho Municipal do Idoso DE FlorianóPOLIS: UMA ANÁLISE A PARTIR DOS MODELOS DE ADMINISTRAÇÃO PÚBLICA, DOS MODELOS DE COPRODUÇÃO DOS SERVIÇOS PÚBLICOS E DOS MODOS DE GESTÃO ESTRATÉGICA E SOCIAL
}

\author{
The Social Control in the Municipal Council for Elderly in Florianópolis: an \\ analysis through the public management models, models of co-production \\ of public services and modes of social and strategic management
}

Thiago Gonçalves Magalhães,

Mestrando do curso de Pós-Graduação em Administração da Universidade Federal de Santa Catarina. Florianópolis, SC, Brasil. E-mail: magalhaesgthiago@gmail.com

Victor Burigo Souza

Mestre em Administração pela Universidade Federal de Santa Catarina. Lages, SC, Brasil. E-mail: victorburigosouza@gmail.com

\section{Resumo}

O estudo buscou identificar as características do controle social no Conselho Municipal do idoso de Florianópolis (CMI). Trata-se de uma pesquisa qualitativa do tipo descritiva e aplicada, na qual os dados foram coletados por meio de entrevistas semiestruturadas, da observação não participante e da análise documental. Com base nos confrontos crítico e reflexivo dos pressupostos teóricos evidenciados e na realidade observada constatou-se que na relação administração pública municipal e CMI predomina o controle social da administração pública sobre a comunidade, além das características da gestão estratégica. No entanto, foi identificado que há características do controle social compartilhado entre a administração pública e a comunidade, por meio do CMI, na implementação de algumas políticas públicas realizadas por organizações governamentais e não governamentais. Características da gestão social também foram identificadas no CMI, como o processo de discussão aberto e com incentivo para participação na discussão acerca das políticas do idoso.

Palavras-chave: Controle Social. Gestão Social. Participação. Administração Pública.

\section{Abstract}

This study aims to identify the characteristics of social control in the Municipal Council for Elderly in Florianópolis (CMI). The study is characterized as a qualitative, descriptive and applied research in which data were collected through semi-structured interviews, non-participant observation and document analysis. Based on critical and reflective comparison between theoretical assumptions and the reality observed we can conclude that regard to the relationship between the municipal government and the CMI there is a predominance of strategic management featuring social control of public management over the community. However, it was identified that there is social control shared between the government and the CMI implementing certain policies by government and non-governmental organizations. Social management characteristics also were identified in the $\mathrm{CMI}$, as the process of open discussion to encourage participation in discussion of policies for the elderly.

Keywords: Social Control. Social Management. Participation. Public Management. 


\section{Contextualização}

A administração pública passa por um momento em que é reivindicada por transformações econômicas, sociais e políticas. Movimentos sociais, protestos e manifestações pelos diversos meios e formas nas comunidades mundo a fora, como a primavera árabe, os movimentos occupy nos Estados Unidos e na Europa e as manifestações de julho de 2013 no Brasil, são reflexos dessas reivindicações. Tais movimentos retratam esse momento que envolve sentimentos de indignação e de esperança, conforme relata Castells (2013), relacionados também ao anseio por maior participação. São mudanças relacionadas aos indivíduos e seus interesses predominantes (HIRSCHMAN, 2002) que refletem na sociedade contemporânea $e$ no setor público.

De provedora absoluta dos serviços públicos oferecidos pelo aparato burocrático do Estado ao compartilhamento de responsabilidades com o mercado para melhorar o equilíbrio fiscal, a administração pública instiga transformações e também é instigada a se transformar. No contexto atual, as mutações desejadas envolvem as demandas comunitárias que vão além de problemas e soluções comuns relacionados à burocracia e ao mercado. Nesse aspecto, essas demandas correspondem a uma forma de pobreza, como aquela descrita por Demo (2003), relacionada à política, podendo ser entendidas como a penúria de modelos de administração pública que correspondam a modos de gestão mais participativos, como o da gestão social, atendendo à multidimensionalidade humana (RAMOS, 1981).

Essa perspectiva que envolve a administração pública faz com que a pesquisa nessa área da ciência se torne mais interessante, uma vez que pode colaborar de forma substantiva para a evolução teórica e prática do campo. Considerando que o estudo pretende construir e analisar teorias em caso empírico é imprescindível que o pesquisador esteja em constante processo de redução sociológica, conforme proposta por Ramos (1996). O referido processo coopera para a quebra do paradigma dominante (SANTOS, 2010) na administração pública, em que predominam pesquisas $e$ modelos pautados na gestão estratégica, colaborando para as pesquisas que buscam possibilidades objetivas (RAMOS, 2014) imbuídas de valores que vão ao encontro do interesse público.
A temática principal dessa pesquisa se insere nesse corolário, uma vez que trata da participação da comunidade em espaços de controle social da administração pública. Dentro desse tema, o foco específico da investigação está relacionado ao controle social exercido por meio dos conselhos municipais.

O controle social é alterado conforme o modelo de administração pública predominante, a existência e a intensidade de participação dos cidadãos na produção do bem público e o modo de gestão que prepondera. O controle social ocorre: da administração pública em relação à comunidade; compartilhado entre a administração pública e a comunidade; da comunidade em relação à administração pública (GOULART, 2011). São exemplos de mecanismos de controle social: órgãos colegiados para a definição e controle das políticas públicas, comitês participativos, organizações sociais de observação e vigilância (VERA; LEVALLE, 2012), conselhos de direitos, conselhos gestores, conferências e fóruns (GOHN, 2011). Participam desses mecanismos, junto à administração pública, organizações privadas e do terceiro setor, além de arranjos comunitários e o próprio cidadão.

Por terem na participação sua essência, os aludidos mecanismos coadunam-se com o conceito de coprodução do bem público ou dos serviços públicos, uma vez que essa também envolve estratégias para a produção dos serviços públicos de que podem participar o aparato público do Estado, as organizações privadas e do terceiro setor, além de arranjos comunitários e do cidadão que, no conjunto, compartilham entre si responsabilidades e poder (SALM, 2014). De acordo com o modelo de administração pública e o modelo de coprodução, predominarão as características de um determinado modo de gestão, repercutindo numa forma de controle social. Esse processo é analisado com base nas dimensões da accountability definidas por Koppell (2005).

Características do modo de gestão social podem ser encontradas em modelos de coprodução, os quais contam com altos níveis de participação, promovendo uma constante automobilização comunitária. A gestão social pode, assim, ser compreendida como um modo de gestão onde a participação ocorre constantemente, ocasionando tomadas de decisões coletivas com base em fatores como a transparência, para alcançar os objetivos que se dirigem ao bem comum da comunidade 
e ao exercício da cidadania (CANÇADO; PEREIRA; TENÓRIO, 2011). Quando há o predomínio desse modo de gestão, por consequência, há o controle social da comunidade em relação à administração pública, impulsionado pela interação dos agentes, promovendo um acompanhamento permanente e coletivo.

Os estudos em gestão social na América Latina e no Brasil tiveram início na década de 1990, conforme demonstram Cançado, Pereira e Tenório (2011). Contudo, não há registros na bibliografia pesquisada em relação a estudos empíricos relacionando a gestão social, controle social e os modelos de administração pública e de coprodução dos serviços públicos. Essa carência também foi verificada no portal de periódicos da Coordenação de Aperfeiçoamento de Pessoal de Nível Superior (CAPES), no período de 1990 até 2015. Assim, a relevância do presente artigo está centrada na carência de estudos empíricos acerca da relação entre o controle social e a gestão social por meio da análise das características que envolvem o modelo de administração pública e os modelos de coprodução dos serviços públicos. Da mesma forma, apresenta importância para as demandas sociais por maior participação e controle da administração pública, haja vista que favorece o rompimento paradigmático da práxis do setor público e a superação da administração pública como um campo multidisciplinar.

Em razão de tal lacuna teórica, o presente estudo tem como objetivo identificar características do controle social no Conselho Municipal do Idoso de Florianópolis (CMI), Santa Catarina, por meio do diálogo entre as principais características que envolvem os modelos de administração pública, os modelos de coprodução dos serviços públicos e os modos de gestão estratégica e social, ambos como escopo teórico e prático para o controle social.

Com foco nesse objetivo, o estudo, após essa (1) contextualização, apresenta o (2) escopo teórico que alicerça a análise realizada acerca do objeto analisado e demonstra o (3) escopo metodológico utilizado na pesquisa para o levantamento $e$ análise dos dados. Em seguida, é analisado o (4) estudo de caso do Conselho Municipal do Idoso de Florianópolis e, por fim, são apontadas as (5) considerações finais e as (6) referências utilizadas.

Antes de dar sequência ao trabalho é necessário esclarecer, em termos gerais, conceitos que nele se fazem presentes. Modelos são generalizações que reproduzem a realidade de forma simplificada e abstrata não podendo esperar que se realizem na íntegra (WEBER, 2004; RAMOS, 1983). Por consequência, os modelos de administração pública e de coprodução dos serviços públicos também se caracterizam como generalizações e simplificações da realidade, devendo essa característica ser levada em conta nessa pesquisa. Por fim, políticas públicas são decisões, ações ou inações promovidas não somente pelos governos, mas também por organizações privadas e do terceiro setor, arranjos comunitários e pelo próprio cidadão (HEIDEMANN, 2014). Realizadas essas clarificações, é possível dar sequência ao trabalho.

\section{Escopo Teórico}

Demonstrada o tema, o objetivo e a estrutura do presente estudo, é necessário que o escopo teórico aprecie a temática do (2.1) controle social, demonstrando as formas e as características que serão empregadas nessa pesquisa. Em seguida, serão analisadas as principais características de cada (2.2) modelo de administração pública, dos modelos de coprodução dos serviços públicos e (2.3) os modos de gestão estratégica e social.

\subsection{O Controle Social}

Dentro da multidisciplinaridade da administração pública, controle social pode ser compreendido pelo viés da ciência social e da ciência política, de acordo com o que estabelece Goulart (2011). Na ciência social, o controle social está relacionado com a finalidade de manter a ordem social. Na ciência política, o controle social pode caracterizar o controle social do Estado ou da administração pública sob a sociedade civil ou comunidade, o controle social compartilhado entre a administração pública e a comunidade, ou o controle social da comunidade sobre a administração pública.

Para melhor compreender os reflexos de cada forma de controle social, é preciso esclarecer fatores ontológicos relacionados ao ser humano como animal político (zoon politikón), definição dada por Aristóteles (2007). Ao realizar essa definição acerca do ser humano, por meio da análise dos símbolos encontrados em 
seu ambiente social (VOEGELIN, 1982), Aristóteles proporcionou o entendimento de que a política é uma dimensão essencial do indivíduo. Nesse sentido, por meio da Teoria da Delimitação dos Sistemas Sociais, Ramos (1981) demonstrou que o homem necessita de espaços de vivência onde possa realizar sua multidimensionalidade - política, social, comunitária e econômica. A esfera pública (ARENDT, 2014) é um espaço propício para a realização da multidimensionalidade humana, da racionalidade substantiva e da ética da convicção, ao contrário da esfera privada, onde há a unidimensionalidade humana, com o predomínio da racionalidade instrumental e da ética da responsabilidade (SALM, 2010).

Esclarecidos esses fatores essenciais para a compreensão dos reflexos do controle social na vida humana, conforme será demonstrado, é possível dar sequencia na identificação das suas perspectivas.

A perspectiva do controle da administração pública sobre a comunidade tem fundamento na corrente de pensadores clássicos do contratualismo moderno. Sob a visão desses autores, o Estado moderno fez com que a humanidade saísse de um estado primitivo fundando uma nova etapa no processo civilizatório (GRUPPI, 2007; HIRSCHMAN, 2002). Sob esse ângulo, a comunidade se configura a partir da instituição do Estado - o povo politicamente organizado, em oposição ao "estado de natureza". Para superá-lo e sobreviver, os indivíduos devem firmar um contrato ou pacto social que restringe suas liberdades e delega a manutenção da ordem social a um ente abstrato - o Estado (BOBBIO, 2007). A administração pública elabora e impõe suas políticas públicas, exercendo, assim, seu controle sobre a comunidade. Os mecanismos de controle social são utilizados para controlar e manipular a comunidade.

Nesse panorama a comunidade é tida como um lócus em que predomina a racionalidade instrumental e a ética da responsabilidade, os interesses privados de indivíduos e grupos organizados, separado do espaço público delimitado pela administração pública (DAGNINO, 2004). O ser humano tende a vivenciar demasiadamente o espaço privado de forma unidimensional, voltado para o econômico.

Na perspectiva do controle social compartilhado entre a administração pública e a comunidade há uma gestão compartilhada, onde a comunidade é chamada a participar da criação e implementação das políticas públicas (DAHL, 2005) em torno do interesse coletivo. A comunidade toma a forma de um espaço associativo em que grupos representam e defendem interesses diversos, e compartilham valores como cooperação, confiança e tolerância, com a finalidade de gerar a coesão social para o funcionamento eficiente da democracia e da economia de mercado.

De acordo com Goulart (2011), tendo como pano de fundo o pensamento de Dahl, o conceito de controle social compartilhado abrange duas dimensões estruturantes que estão interligadas, sendo a participação política e accountability da administração pública. Para esse autor, a eficácia de novas institucionalidades, por exemplo, os conselhos de gestão, dependem das oportunidades de participação e promoção da accountability comprometidas com os princípios democráticos. Nesse sentido, a accountability está relacionada não simplesmente a símbolos ou gestos realizados por determinados mecanismos, mas como uma orientação relacionada a valores (ETZIONI, 2014) que tenham como base não apenas a ética da responsabilidade, mas também a ética da convicção (RAMOS, 1983).

A accountability, segundo Koppell (2005), possui dimensões como transparência, imputabilidade, controle, responsabilidade e responsividade. A transparência estaria relacionada com a publicidade que a administração pública dá aos fatos relacionados à suas ações, desempenho, erros e acertos. A imputabilidade se refere ao fato de a administração pública enfrentar consequências por causa de seu desempenho, tanto quanto a gratificações em casos positivos, quanto a punições em casos negativos. O controle está relacionado com a realização da vontade do principal ou comitente que controla a administração pública. A responsabilidade diz respeito à observação das regras formais ou informais por parte da administração que lhe são imputadas. Por fim, a responsividade corresponde à consideração da administração pública da vontade substantiva que lhe cabia atender, ou seja, ao interesse público.

No controle social compartilhado, o indivíduo, como membro dos grupos organizados da comunidade tem a oportunidade de agir no espaço público de forma multidimensional. Essa ação não se dá apenas com base na racionalidade instrumental e na ética da responsabilidade, mas também na racionalidade substantiva e na ética da convicção. 
O controle social compartilhado apresenta limitações quando se baseia na necessidade de haver grupos organizados da comunidade. O controle social pode, também, ser realizado pelo cidadão, na sua participação direta na decisão pública conforme a perspectiva de democracia deliberativa de Habermas (2003). Dessa forma, a comunidade pode realizar o controle social estando organizada ou não, em grupos formais e informais ou pelo próprio cidadão de forma individual.

Dentro dessa perspectiva, o controle social da comunidade sobre a administração pública se realiza, então, por meio da participação do indivíduo, organizado em grupos ou não, na esfera pública, possibilitando o exercício de sua multidimensionalidade humana. Nessa ação, onde há tensão entre racionalidades $e$ éticas, prepondera a racionalidade substantiva e a ética da convicção. Esse conceito é fruto da construção de uma nova visão da comunidade, diferente daquela relacionada à luta de classes, eivada de profundas contradições advindas da dominação e exploração do trabalho pelo capital, que já não corresponde mais a realidade social do ocidente. Aos poucos essa visão cede espaço para uma concepção de comunidade como lugar de múltiplos conflitos que precisam ser solucionados pela via da participação cidadã democrática e não pela via revolucionária com embates violentos entres classes (ROBERTS, 2004; ARNSTEIN, 1969).

Assim, diante dessa perspectiva o controle social da comunidade sobre a administração pública é realizado diretamente pelo cidadão. Cidadão entendido aqui dentro de um conceito de cidadania democrática participativa (PATEMAN, 1992) que carrega um potencial transformador voltado ao interesse público. Denhardt e Denhardt (2011) conceituam o interesse público como resultante da participação da comunidade, organizações produtivas e administração pública na deliberação pública com o compartilhamento de valores baseados no desenvolvimento comunitário.

\subsection{Os Modelos de Administração Pública}

A administração pública altera a forma de produzir os serviços públicos e de se relacionar com a comunidade conforme seu modelo. O conceito de administração pública passou por longos debates acadêmicos até atingir as concepções atuais que consideram essa, uma área multidisciplinar da ciência (FADUL;
DE AGUIAR MAC-ALLISTER DA SILVA; PINTO DA SILVA, 2012). De modelos voltados para a burocracia e o mercado, até um modelo com premissas extraídas da democracia e da coprodução dos serviços públicos a administração pública encontra diferentes formas de produzir os serviços públicos. Sua relação com a comunidade também se altera conforme o modelo de administração adotado, principalmente quanto aos aspectos da participação e, consequentemente, do controle social.

No primeiro modelo, da antiga ou velha administração pública, a produção dos serviços públicos é concentrada no aparato burocrático do Estado, não havendo incentivos à participação cidadã e consequentemente a coprodução dos serviços públicos. Predominam as características da burocracia, como controle e impessoalidade, na produção dos serviços públicos. Nesse modelo o controle social da comunidade em relação à administração pública é praticamente inexistente. Em relação às dimensões da accountability a transparência vai se limitar as determinações legais. A imputabilidade ocorre apenas quando a lei ou norma estabelecida não foi seguida, independente da eficiência ou eficácia dos serviços públicos. O controle diz respeito apenas às normas existentes. A responsabilidade e a responsividade também seguirão apenas aos anseios legais. É possível dizer que nesse modelo há maior controle da administração pública sob a comunidade.

No segundo modelo, da nova gestão pública, são incorporadas as características do setor privado. O mercado é utilizado para a produção dos serviços públicos e a participação se dá por meio da transferência da produção dos serviços públicos para o setor privado, na busca de maior eficiência e eficácia. Com isso, há coprodução dos serviços públicos, contudo, com o interesse de diminuir os custos e enxugar a máquina pública do Estado. A transparência se dará de acordo com a lei e as exigências de competição. A imputabilidade ocorre de acordo com a lei, com o objetivo de melhorar a eficiência. O controle é de acordo com as vontades do mercado. A responsabilidade tem por base as regras, que são impostas para atender as necessidades de competição. A responsividade ocorre de acordo com as expectativas de competição. Nesse modelo, influenciada pelas leis de mercado e pelo in- 
teresse da clientela, o controle social é compartilhado entre a administração pública e a comunidade.

O terceiro modelo é o do novo serviço público. Esse modelo foi desenvolvido por Denhardt e Denhardt (2011), como um modelo normativo, ou seja, um modelo ideal que é pautado nos princípios da democracia e da participação na coprodução dos serviços públicos. Nesse modelo há o compartilhamento de responsabilidades entre a administração pública e a comunidade na produção dos serviços públicos. A transparência ocorre constantemente, permitindo que a comunidade verifique os fatos associados ao desempenho, acertos e erros da administração pública, podendo, assim, tomar decisões de forma mais consciente nos espaços de participação e de coprodução. A imputabilidade ocorre não somente por erros ou acertos com base na lei, mas também em efeitos substantivos das ações coproduzidas. $\mathrm{O}$ controle ocorre com base na realização da vontade da comunidade. A responsabilidade é de acordo com regras formais e informais, com destaque para a segunda que está relacionada com os valores que preponderam na comunidade e nem sempre podem ser formalizados por meio de regras ou leis. E a responsividade é verificada conforme os serviços públicos são coproduzidos atendendo plenamente as expectativas substantivas da comunidade. Há o controle social compartilhado entre a administração pública e a comunidade, com base em valores democráticos e na coprodução dos serviços públicos.

É importante ressaltar que o aparato administrativo do Estado, ao exercer o controle social, está sobre influência das características do modelo de administração pública predominante. Apesar de o controle social ser compartilhado entre a administração pública e a comunidade no modelo da nova gestão pública e do novo serviço público, esse possui características diferentes devido ao modelo de administração pública preponderante.

\subsection{Os Modelos de Coprodução dos Serviços Públicos}

A coprodução dos serviços públicos, por envolver a participação de diferentes agentes junto ao aparato público do Estado, colabora para a formação dessa cultura política que tem como objeto o interesse público. A intensidade da participação, a forma de controle so- cial $e$ as dimensões de accountability variam de acordo com o modelo de coprodução dos serviços públicos desenvolvidos por Salm e Menegasso (2010).

O modelo de coprodução nominal é uma estratégia para a produção dos serviços públicos, por meio de compartilhamento de responsabilidades entre pessoas da comunidade, preferencialmente voluntários, e o aparato administrativo de Estado. O propósito é de tornar eficientes esses serviços, por meio de uma manipulação do cidadão para que esse participe de forma passiva e entenda que a administração pública faz algo em seu benefício. Quanto às dimensões da accountability, a transparência é limitada às previsões da lei. A imputabilidade ocorre apenas quando a legislação não foi seguida. O controle diz respeito apenas às normas existentes. A responsabilidade também seguirá as determinações da lei. A responsividade atende aos anseios da lei e do próprio Estado como organização administrativa. É possível dizer que nesse modelo há o controle da administração pública sob a comunidade. Esse modelo de coprodução se aproxima do modelo da antiga ou velha administração pública, na qual há predominância do controle social da administração pública sob a comunidade.

A coprodução simbólica é uma estratégia para envolver os cidadãos na produção dos serviços públicos para demonstrar a presença ou eficácia do Estado e obter anuência em relação a certas decisões por meio de consultas. Diferentemente do modelo anterior, esse, devido à consulta, pode despertar o cidadão para que procure participar de forma mais efetiva. A transparência, a imputabilidade, o controle, a responsabilidade e a responsividade ocorrem conforme a lei e o interesse da organização administrativa do Estado. Nesse modelo, o controle social é da administração pública sob a comunidade, tendo características que podem se aproximar da antiga administração pública e da nova gestão pública.

O modelo da coprodução funcional é uma estratégia utilizada pelo aparato público do Estado para produzir os serviços públicos de maneira mais eficiente e eficaz, com a participação do indivíduo, do grupo ou da coletividade, que são vistos como clientes. O Estado pode oferecer recursos ou incentivos para a comunidade participar da produção dos serviços públicos, com base nos resultados e no menor custo. A transparência segue a lei e a demanda dos clientes. 
A imputabilidade é conforme a lei definida pelo interesse dos clientes. O controle é exercido pelo aparato administrativo do Estado conforme a vontade dos clientes. A responsabilidade e a responsividade são aos clientes e a organização administrativa do Estado. Tem aproximação com a nova gestão pública e o controle social é compartilhado entre a administração pública $e$ a comunidade ou clientela.

A coprodução representativa com sustentabilidade, por meio da interação que ocorre entre os cidadãos de uma mesma comunidade gera uma forma de poder que está além do poder do Estado. Resulta da sinergia que se estabelece na realização dos serviços públicos de que participam os cidadãos, as organizações da comunidade e o aparato administrativo do Estado que, no seu conjunto, interagem em prol do bem comum. As dimensões da accountability são essenciais para esse modelo. A transparência é baseada na legislação que segue as demandas da comunidade. A imputabilidade ocorre conforme a lei e os valores democráticos que a compõe. O controle é exercido pelo aparato administrativo do Estado, conforme a vontade dos cidadãos que também participam e realizam controle de forma efetiva. A responsabilidade ocorre conforme as normas formais e informais, com destaque para a segunda, que é influenciada por valores substantivos $e$ democráticos. A responsividade é à comunidade $e$ ao cidadão. Essas características se alinham com as do novo serviço público. O controle social é compartilhado entre a administração pública e a comunidade.

A coprodução para a automobilização comunitária é uma estratégia para a realização dos serviços públicos de que participa toda a comunidade, orientada por princípios éticos e pela democracia normativa, com o propósito de manter a sociedade permanentemente mobilizada. A comunidade é permanentemente mobilizada nesse modelo, exercendo poder sobre na superação da organização burocrática do Estado. As demais características são semelhantes às da coprodução representativa com sustentabilidade. Já o controle social é da comunidade sobre o Estado.

Analisadas as características de cada modelo de coprodução dos serviços públicos em relação ao modelo de administração pública e o controle social é possível verificar o modo de gestão que se aproxima de cada um, entre a gestão estratégica e a gestão social.

\subsection{Os Modos de Gestão Estratégica e Social}

A gestão estratégica e a gestão social podem ser consideradas como dicotomias dentro dos estudos publicados recentemente. A primeira preconiza uma estrutura hierarquizada que dificulta a participação efetiva dos sujeitos no processo de tomada de decisão nas organizações. Já a segunda é orientanda pelos princípios da cidadania deliberativa, objetiva a emancipação dos indivíduos, possibilita o exercício efetivo de sua cidadania e de seus direitos no controle social da administração pública (TENÓRIO, 2013).

Segundo Pimentel e Pimentel (2010), a gestão estratégica apresenta como principais aspectos, o lucro como seu objetivo, o mercado como protagonista, predominância da racionalidade instrumental, comunicação vertical e com restrição ao direito da fala, processo decisório centralizado e do tipo top down, entre outros. Já a gestão social, caracteriza-se por objetivar o interesse coletivo de caráter público, protagonismo da sociedade civil organizada, racionalidade substantiva predominante, comunicação do tipo dialógica e com pouca ou nenhuma restrição ao direito da fala, processo decisório coletivo, descentralizado e participativo, entre outros.

A gestão estratégica analisada com base nas dimensões da accountability terá: a transparência de acordo com a lei e as exigências de competição; a imputabilidade conforme a lei, com o objetivo de melhorar a eficiência; o controle de acordo com as vontades do mercado; a responsabilidade com base nas regras, que são impostas para atender as necessidades da organização e de competição; a responsividade de acordo com as expectativas de competição. O controle social é exercido pela administração pública sobre a comunidade. O caráter burocrático no modelo da velha administração pública, bem como a busca pela eficiência na nova gestão pública são perspectivas que se aproximam do modelo de gestão estratégica. A gestão estratégica, analisada por essas dimensões se aproxima dos modelos de coprodução nominal, coprodução simbólica e coprodução funcional. Quando preponderam características da nova gestão pública e da coprodução funcional o controle social, na gestão estratégica, poderá ser compartilhado. 
Ao tratar dos aspectos relativos ao conceito de gestão social, Tenório (2005) norteia esse campo, ainda em formação, ao entender a gestão social como possibilidade de uma gestão democrática, participativa cujo processo decisório apresenta como pressuposto basilar a promoção de um espaço onde todos tenham o direito da fala, sem nenhum tipo de coação da autoridade decisória compartilhada entre os sujeitos participantes. Em síntese, a gestão social preconiza a prática de valores inerentes à democracia, participação, e o diálogo como elementos-chave (BOULLOSA; SCHOMMER, 2008).

Paes de Paula (2005) propõe uma aproximação da gestão social com a gestão pública no sentido da construção de uma administração pública societal. Dessa forma, a gestão social e suas premissas teóricas apresentam grande valor para a administração pública e para a coprodução dos serviços públicos, uma vez que também é definida como um conjunto de práticas em que o diálogo e a discussão direcionam os esforços em prol do alcance dos objetivos que se dirigem ao bem comum da comunidade e do exercício da cidadania (CANÇADO; TENÓRIO; PEREIRA, 2011).

$\mathrm{Na}$ gestão social as dimensões da accountability se dão da seguinte forma: a transparência das informações é requisito essencial, pois nesse modelo as informações devem estar acessíveis aos sujeitos para que tenham condições de participação efetiva; a imputabilidade ocorre não somente por erros ou acertos com base na lei, mas também em efeitos substantivos das ações coproduzidas; o controle ocorre de forma constante pela própria comunidade; a responsabilidade é de acordo com regras formais e informais, com destaque para a segunda que está relacionada com os valores que preponderam na comunidade e nem sempre podem ser formalizados por meio de regras ou leis; a responsividade é verificada conforme os serviços públicos são coproduzidos atendendo plenamente as expectativas substantivas da comunidade, ou seja, no lugar do foco na eficiência têm-se a legitimidade.

No modo de gestão social, o controle social é da comunidade sobre a administração pública. O controle social compartilhado também se aproxima das características da gestão social quando alinhado aos pressupostos do novo serviço público. Esse modelo de administração pública e a gestão social se complementam, uma vez que são pautados nos princípios da democracia e da participação direta da comunidade e não apenas por grupos organizados. Desse modo, as características do modo de gestão social estão relacionadas com os modelos de coprodução representativa com sustentabilidade e ao de automobilização comunitária, uma vez que esses modelos têm como premissa a participação efetiva da comunidade e seus cidadãos.

Realizada a análise dos modos de gestão estratégica e gestão social, destacando suas semelhanças com os modelos de administração pública e os modelos de coprodução dos serviços públicos, é possível dar sequência a perseguição do objetivo do presente trabalho, por meio da elucidação do escopo metodológico e do estudo de caso.

\section{Escopo Metodológico}

O estudo é caracterizado como qualitativo, evidenciando as características básicas descritas por Godoy (1995): conforme essa perspectiva um fenômeno pode ser melhor compreendido no contexto em que ocorre devendo ser analisado numa perspectiva integrada. Por esse motivo, o pesquisador deve ir a campo buscando captar o fenômeno em estudo a partir da perspectiva das pessoas nele envolvidas, considerando todos os pontos de vista relevantes. Trata-se ainda de uma pesquisa aplicada que, de acordo com Vergara (2007), objetiva gerar conhecimentos para aplicação prática, dirigidos à solução de problemas específicos, envolvendo verdades e interesses locais. Como estratégia de pesquisa fez-se uso do estudo de caso descritivo que possibilita, conforme Godoy (2006), o estudo profundo de um determinado objeto com o objetivo de examinar detalhadamente um caso particular.

$\mathrm{Na}$ coleta de dados foram utilizadas a entrevista semiestruturada e a observação não participante, que foram aprovadas por unanimidade dos conselheiros em uma plenária realizada no mês de setembro de 2014. De acordo com Oliveira (2007, p. 37) “[...] a entrevista semiestruturada tem como principal objetivo compreender os significados que os entrevistados atribuem às questões e situações relativas ao tema de interesse". Foram realizadas no total de oito entrevistas nos meses de outubro e novembro de 2014, uma entrevista com a presidente do CMI, uma entrevista com a secretária executiva e seis entrevistas com os conselheiros. 
Foi realizada pesquisa documental de atas das reuniões e do estatuto do conselho municipal do idoso. Ainda com o objetivo de complementar a coleta dos dados fez-se a observação não participante durante as duas Plenárias ocorridas nos meses de outubro e novembro, que de acordo com Minayo (1994) possui um papel essencial no estudo de caso qualitativo, pois permite apreender aparências e comportamentos.

Foi realizada a análise qualitativa dos dados através do confronto crítico e reflexivo dos pressupostos teóricos evidenciados e a realidade observada através do estudo de caso aplicado. A metodologia utilizada para análise dos dados foi a análise qualitativa das entrevistas e documentos, buscando a partir das dimensões da accountability (transparência, imputabilidade, controle, responsabilidade e responsividade) fazer o confronto crítico e reflexivo com os demais pressupostos do escopo teórico.

\section{Estudo de Caso}

Com base nos pressupostos teóricos que apresentam os principais conceitos relacionados ao controle social e sua relação com o modo de gestão social, é possível, por meio dos fundamentos metodológicos apresentados, analisar o objeto empírico da pesquisa. Com esse propósito, é apresentada uma contextualização do objeto de estudo (4.1), propiciando o entendimento acerca das principais características. Essas características podem ser identificadas na descrição dos dados (4.2) da pesquisa, contendo informações relevantes à análise crítica e reflexiva (4.3) da realidade com os pressupostos teóricos.

\subsection{O Conselho Municipal do Idoso de Florianópolis}

O Conselho Municipal do Idoso de Florianópolis (CMI) foi criado pela Lei n. 5.371, de 24 de setembro de 1998, revogada e substituída pela Lei n. 7.694, de 17 de outubro de 2008. É um órgão colegiado, deliberativo, normativo, fiscalizador e consultivo, de caráter permanente e de composição paritária por representações do governo municipal e sociedade civil. É composto por 20 representações, 10 conselheiros titulares e respectivos suplentes, indicados pelo Prefeito
Municipal, representantes de órgãos governamentais municipais e 10 conselheiros titulares e respectivos suplentes, eleitos em fórum próprio, representantes de organizações não governamentais.

A estrutura de funcionamento do CMI envolve a sessão plenária, mesa diretora, secretaria executiva $e$ as comissões permanentes. A sessão plenária é a instância deliberativa do Conselho constituída por reuniões ordinárias ou extraordinárias. A Mesa Diretora é composta pelo Presidente, Vice-Presidente, Primeiro Secretário e Segundo Secretário, possui composição paritária, governamental e não governamental, respeitando a alternância nos cargos a cada dois anos com prioridade para a presidência ser ocupada por conselheiros representantes de organizações não governamentais. A Secretaria Executiva, composta por um coordenador, servidor público da Prefeitura Municipal, possui a função de prestar serviços, suporte técnico $e$ administrativo ao $\mathrm{CMI}$, mesa diretora e comissões. As comissões permanentes possuem caráter de fiscalização, controle orçamentário, acompanhamento e controle da execução das políticas públicas e de divulgação das ações do CMI.

Dentre as principais atribuições do CMI, de acordo com a Lei n. 7.694, de 2008, e o Regimento Interno, tem-se a deliberação das diretrizes e outras questões relacionadas à política de atenção a pessoa idosa. O estabelecimento de normas que oficializam decisões da sessão plenária e regulamentam a execução da política de atenção da pessoa idosa. Acompanhamento e controle do funcionamento dos programas e instituições governamentais e não governamentais que constituem a rede de atenção de atenção e proteção à pessoa idosa. $\mathrm{O}$ monitoramento e avaliação da efetivação da política de atenção à pessoa idosa é uma proposição de ações.

Ante a descrição do CMI é possível verificar que o objetivo intrínseco à sua existência é a realização do controle social na formulação e implementação de políticas públicas voltadas para o idoso. O relato dos dados permite revelar evidências da realização ou não do controle social por meio do CMI.

\subsection{Descrição dos Dados}

$\mathrm{Na}$ descrição dos dados serão apresentadas as entrevistas com os membros do CMI, delimitadas em 
quatro tópicos, que consistem: na percepção do entrevistado acerca das atribuições do CMI em relação as suas principais atividades; nas ações desempenhadas; na gestão do conselho acerca da divulgação de suas atividades, processo de tomada de decisão, participação e o relacionamento com a comunidade; no controle acerca da formulação e implementação de políticas públicas. As entrevistas, que serão descritas literalmente, foram realizadas com a presidente (E1), a secretária executiva (E2), três conselheiros representantes de organizações não governamentais (E3); (E4); (E5) e três conselheiros representantes das organizações governamentais (E6); (E7); (E8). Os entrevistados permitiram ser identificados nesta descrição por ocupação, nome ou cargo. Além das entrevistas, será apresentada a percepção em relação à observação das reuniões do CMI.

O primeiro tópico de análise consiste na percepção dos entrevistados em relação às atribuições do CMI. Nas falas dos entrevistados, foi identificado que há percepção, destes, em relação às funções que o CMI deve desempenhar, vai ao encontro do que está estabelecido, acerca de seu funcionamento, na legislação e no seu regimento interno. Apesar de haver essa percepção entre os conselheiros entrevistados, eles afirmam que existem dificuldades para o pleno exercício das atribuições do CMI. Esse fato pode ser constatado nas seguintes falas:

O objetivo, o papel principal do conselho é a defesa dos direitos da pessoa idosa, e como plano de fundo, ele tem a política, o controle, a execução, avaliação e monitoramento da politica municipal do idoso, e com certeza o controle social, que eu não vejo que o conselho esteja fazendo, esteja, vamos dizer atuando no controle social, eu não vejo [...]. (E2, 2014).

Eu penso que, o papel do conselho é o controle das políticas do idoso, tanto por parte do governo, quanto a fiscalização dos serviços prestados ao idoso por outras organizações. [...] Assim, eu penso que essa cultura de participação ainda é muito nova, apesar de estar estabelecido na constituição de 88, então inda requer um amadurecimento [...]. (E7, 2014).

As principais dificuldades enfrentadas pelo CMI, apontadas pelos conselheiros, no que tange à consecução de suas atribuições são: a falta de conhecimento e interesse por parte dos conselheiros e a relação distanciada entre o conselho e o governo municipal.

O segundo tópico está relacionado com as ações desempenhadas pelo CMI. Na concepção dos conselheiros, a fiscalização das instituições de longa permanência para idosos realizada em parceria com entidades e órgãos da administração pública estadual, como o Ministério Público, o Corpo de Bombeiros e a Vigilância Sanitária, do Estado de Santa Catarina, consiste na ação de maior importância exercida pelo CMI. Além disso, outras ações foram evidenciadas, como a fiscalização, a orientação e o cadastro dos grupos de convivência para idosos. Dentre essas atividades, o CMI também busca averiguar as denúncias realizadas para o próprio $\mathrm{CMI}$, além de incentivar e organizar outras políticas de controle social como eventos e conferências, conforme as falas:

\section{A fiscalização das ILPIs junto com o MP é muito importante, e eu sempre incentivo, eu fui a várias. [...]. tem também a fiscalização das denúncias que recebemos, e averiguamos, se for a violência nas instituições nós buscamos intervir, se for na família buscamos o CEPRED [...]. (E1, 2014). \\ "Acho que a fiscalização das Instituições delonga permanência né, a deliberação das questões referentes à política do idoso, e os eventos e conferências quando realizamos [...] (E6, 2014).}

O terceiro tópico de análise é referente à gestão do CMI quanto ao incentivo à divulgação das informações, processo de tomada de decisão e a participação.

Quanto à divulgação das informações ficou evidente que o CMI apresenta dificuldades no processo de comunicação, nas falas dos entrevistados, ficou evidente que o conselho possui dificuldade no repasse das informações sobre o andamento das atividades, bem como possui também dificuldade na comunicação com a comunidade, acarretando no desconhecimento por parte da mesma, do conselho e das reuniões. $\mathrm{O}$ que é demostrado na seguinte fala:

É difícil chegar no idoso né, nós buscamos repassar as datas das plenárias quando vamos visitar os grupos de convivência, entregamos o papel com as datas quando eles vem aqui também, e atualizamos no nosso blog, mas aí vai um ou outro na plenária. (E2, 2014). 
A divulgação do CMI é apontada pelo entrevistado E5 (2014) como um dos fatores para não haver muita participação do idoso e o conselho não ser tão forte.

Em relação ao processo de tomada de decisão, ficou evidente que há no CMI um espaço aberto para a participação de forma igualitária, conforme é salientando nas seguintes falas: "Sim, eu acho que ninguém fica sem ser ouvido né, a gente sempre quer que os conselheiros falem a sua opinião né na votação da reunião, mas sempre são os mesmos que acabam falando mais, e outros vão, como se diz, na onda né [...]" (E1, 2014).

Nas plenárias todos podem opinar né, até quem não é conselheiro, mas só nós que temos o direito ao voto. [...] então eu acho que tem um espaço aberto né, pra discussão, mas o que eu percebo muitas vezes é mais a falta de interesse mesmo [...] (E4, 2014).

Todo mundo pode falar né, eu como sou novo, eu ainda não entendo muito, mas tem esse espaço para todos, até mesmo quem não é conselheiro pode participar da discussão, só não vota daí, mas pode falar, e depois nós votamos a favor ou contra sobre o que tá sendo discutido [...]. (E8, 2014).

Os temas são discutidos pela mesa diretora $e$ pelas comissões, no entanto, as decisões somente são tomadas nas reuniões plenárias mensais, nas quais, os conselheiros e a qualquer pessoa presente na reunião podem discutir a respeito dessas questões, que posteriormente são decididas por meio do voto dos conselheiros.

A participação pode ser observada por dois aspectos: a participação dos conselheiros, representantes das organizações governamentais e não governamentais; e a participação da sociedade civil. Na participação dos conselheiros, os entrevistados, tanto os componentes da mesa diretora quanto os conselheiros representantes das organizações governamentais e não governamentais, elucidaram um problema frequente no CMI. É a falta de interesse de alguns conselheiros, principalmente aqueles que representam as organizações governamentais (E1, 2014; E2, 2014; E5, 2014), o que também pode ser constatado na fala a seguir:

Eu vejo assim né, que alguns conselheiros principalmente os representantes da ala governamental não possuem muito interesse sabe, mais porque são indicados sabe, ai eles não entendem da política do idoso. [...] Ai tem as capacitações pro conselheiro novo né, mas mesmo assim eles faltam muito e tem muita rotatividade. (E6, 2014).

De maneira geral, os entrevistados percebem uma maior passividade dos conselheiros representantes das organizações governamentais, pois muitas vezes esses conselheiros são indicados, mas não possuem quaisquer relações com a área das políticas relacionadas às pessoas idosas e, por esse motivo, acabam por desconhecer do que essas políticas tratam.

$\mathrm{O}$ quarto tópico consiste no controle que o $\mathrm{CMI}$ exerce na formulação e implementação de políticas públicas. Na implementação das políticas públicas realizadas pela administração local e por organizações não governamentais no âmbito da saúde, educação, $e$ assistência na permanência de idosos, fica evidenciado que o $\mathrm{CMI}$ exerce maior controle social. A seguir apresenta-se a fala que demonstra como o CMI realiza a fiscalização dessas organizações:

O conselho ele têm, ele fiscaliza e normatiza, da direções e vivências dos grupos, os grupos de idosos [...], são fiscalizados pelo conselho, ele trabalha junto com o Ministério Público, todas as casas de repouso de idoso, as ILPIs, né, são as casas de permanência. Todas as casas são inscritas no conselhos e são visitadas, são fiscalizadas e recebem então um certificado de inscrição pra poder funcionar, caso não tenha esse certificado, o Ministério geralmente fecha [...]. E nesse caso então, o conselho atende as denuncias, então por exemplo alguém da comunidade vai lá e denuncia, ó lá na minha comunidade funciona uma casa de idoso, nesse momento ela está funcionando clandestinamente, no momento que o conselho toma consciência, o conselho vai, visita faz uma vistoria, se tiver alguma coisa irregular, manda um relatório pro Ministério Público [...]. (E3, 2014).

Fica identificado no aspecto da implementação das políticas públicas, que o CMI fiscaliza e controla as atividades realizadas por essas organizações, em parceria com outros órgãos da administração pública. Nesse aspecto, a comunidade age como parceira ao realizar denúncias relacionadas às atividades desempenhadas por essas organizações.

A descrição da percepção dos entrevistados acerca das atribuições, das ações desempenhadas, da 
gestão e do controle realizado pelo $\mathrm{CMI}$ e a percepção da observação possibilitam uma aproximação do caso empírico com o escopo teórico delineado no estudo. Dessa forma, apresenta-se a seguir uma análise crítica-reflexiva dos dados.

\subsection{Análise Crítica-Reflexiva dos Dados}

Apresentado o escopo teórico que embase a pesquisa, o escopo metodológico e a descrição do objeto de estudo e dos dados é possível realizar a análise crítica-reflexiva dos dados. Os tópicos analisados na descrição dos dados serão discutidos a partir das principais características do controle social. Essa análise será realizada por meio das categorias de análise extraídas das dimensões da accountability: transparência; imputabilidade; controle; responsabilidade; e responsividade. Essas dimensões são apresentadas na literatura como aspectos fundamentais para o controle social.

A dimensão da transparência é tratada por Cançado, Pereira e Tenório (2013) como requisito essencial à gestão social e ao controle social. Em relação ao objeto de estudo, a transparência é fundamental para que o CMI realize o controle social da formulação e implementação das políticas públicas. Como a administração pública municipal tem sido a principal formuladora e implementadora de políticas públicas para o idoso, é necessário analisar a transparência desse processo nas relações entre a Prefeitura e o CMI e o CMI e a comunidade.

As entrevistas E.3; E.5; e E.7 mostram que há pouca comunicação entre a administração pública municipal e o CMI. Nas atas das reuniões realizadas entre os anos de 2013 e 2014, há poucos assuntos deliberados que envolvem informações das ações, erros e acertos enviados ao CMI pela administração pública municipal. Essa escassez de transparência do município em relação às suas ações, desempenho, erros e acertos no planejamento e execução de suas políticas para o idoso, compromete a atividade do CMI. Houve consulta apenas nos casos em que a legislação determinava que o CMI deliberasse em relação a determinado assunto. A transparência, então, é realizada apenas quando a legislação determina que o município consulte ou preste conta ao $\mathrm{CMI}$ acerca de determinado assunto.
Na relação CMI e comunidade, a transparência é precária, uma vez que há poucos mecanismos que levem até a comunidade informações relacionadas às ações, desempenho, erros e acertos do conselho, bem como a disponibilização das informações acerca das decisões. Nesse aspecto, os entrevistados (E.2; E.4; E.7) afirmam que as reuniões são abertas, que qualquer cidadão tem direito a participar e discutir os temas das reuniões e ter acesso as atas do CMI. Contudo, fica evidente que as informações referentes ao CMI não chegam até a comunidade. A descrição das entrevistas e a análise dos dados coletados demonstram que o CMI possui o desafio de melhorar seu processo de transparência. Há poucos mecanismos de comunicação que realmente levam as informações até o cidadão. O site da Prefeitura, por exemplo, contem conteúdo específico sobre o CMI. Todavia, há poucas informações nesse meio de comunicação limitado a parcela da comunidade que tem acesso à internet. Esses fatos demonstram que a transparência em relação à comunidade está prejudicada, uma vez que não há uma estratégia ampla de divulgação das atividades e atribuições do CMI para a comunidade. Essa estratégia poderia colaborar para a participação efetiva dos cidadãos, indo além da simples participação representativa por meio dos conselheiros.

Essa dimensão se aproxima ao modelo da velha administração pública, e ao modelo de coprodução simbólica uma vez que, conforme observado, a transparência ocorre conforme as previsões legais e quando há o interesse da organização, nesse caso, a administração pública municipal e o CMI como órgão institucionalizado.

A imputabilidade ocorre em relação aos serviços públicos executados diretamente pela administração pública e pelos serviços produzidos pelas organizações não governamentais. As consequências que essas organizações sofrem quando há denúncias em relação às irregularidades e problemas relacionados à prestação dos serviços públicos são exemplos da imputabilidade. Conforme relatado nas entrevistas E.1; E.7; nesses casos, há uma averiguação realizada pelo $\mathrm{CMI}$ em parceria, principalmente, com o Ministério Público estadual, das denúncias recebidas. Essa investigação pode ocasionar em sansões aos prestadores dos serviços e até mesmo no fechamento das entidades irregulares. Fica evidente que pode haver sanções conforme o de- 
sempenho da administração pública e das organizações não governamentais que apresentam irregularidades ao desempenharem suas atividades. Nessa perspectiva percebe-se uma aproximação com os modelos de administração pública da velha administração pública e o modelo de coprodução nominal e simbólica, pois a imputabilidade ocorre apenas quando a legislação não foi seguida.

O controle, na perspectiva de Koppell (2005), relacionado com a realização da vontade do principal, ou comitente que controla a administração pública, pode ser observado na relação administração pública municipal e CMI de forma limitada. Como já foi demonstrado, o CMI tem a competência de deliberar acerca das políticas públicas referentes aos idosos que estão sendo planejadas e implementadas. Contudo, - CMI é consultado apenas quando a lei exige, dessa forma, a dimensão do controle é limitada em relação à execução, por parte da administração pública, de suas ações, característica semelhante da velha administração pública e dos modelos de coprodução nominal e simbólica.

A dimensão da responsabilidade em relação à administração pública municipal é atendida parcialmente. Em relação às regras formais, na maioria das vezes a administração pública municipal cumpre com o que está prescrito, como por exemplo, quando é exigido por lei que determinado tema seja deliberado no CMI. Já em relação às regras informais, aqui relacionadas com aspectos valorativos, a administração pública ignora a necessidade de participação da comunidade na esfera pública. Essas características estão presentes na velha administração pública e no modelo de coprodução simbólica.

A responsividade também é limitada. Os dados coletados nas entrevistas demonstram que a administração pública municipal dialoga muito pouco com o CMI, tomando as decisões que estão relacionadas a políticas voltadas para os idosos. Isso demonstra que o interesse público não é a prioridade, preponderando o interesse da organização pública como aparato burocrático do Estado. Em relação ao processo de tomada de decisão dos conselheiros, a responsividade também é limitada. O interesse público é lesado, uma vez que os membros do CMI são representantes governamentais ou representantes das organizações não governamentais. Em outras palavras, representam interesses de organizações públicas ou privadas e não puramente os interesses da comunidade. Essa dimensão se aproxima dos modelos da velha administração pública $e$ da nova gestão pública. Também pode ser associada aos modelos de coprodução simbólica e funcional.

A partir das dimensões da accountability analisadas anteriormente e correlacionadas com os modelos de administração pública e os modelos de coprodução dos serviços públicos, é possível identificar as características do modo de gestão estratégica e social relacionadas ao controle social no CMI.

Nas políticas públicas voltadas à pessoa idosa, há um processo de gestão que se aproxima da gestão estratégica descrita por Pimentel e Pimentel (2010), conforme o que pode ser constatado nas falas dos entrevistados, na observação realizada e na análise dos documentos. Esse fato é perceptível uma vez que não há participação efetiva do $\mathrm{CMI}$ e da comunidade no processo de decisão acerca das políticas públicas, o qual é centralizado na administração pública municipal e do tipo top down.

Em relação à gestão do $\mathrm{CMI}$ há algumas características mais próximas do modo de gestão social descritas por Tenório (2013). Conforme salientado pelos entrevistados, há um processo de tomada de decisão coletiva, em que há um espaço aberto para discussão e deliberação das decisões para os conselheiros $e$ a mesa diretora. Existe incentivo à participação na discussão acerca das questões a serem decididas. No entanto, o CMI tem o desafio de melhorar o processo de comunicação com a comunidade e a inclusão dos cidadãos no processo de discussão acerca das questões do conselho, uma vez que eles são representados no processo de deliberação pelos conselheiros representantes das organizações não governamentais.

Fica evidente, na fala dos entrevistados, o reconhecimento de que a integração entre os conselheiros e os cidadãos nas discussões e no processo de deliberação é de grande importância para impulsionar o controle social, e proporcionar uma maior representatividade do conselho perante a administração pública. Além disso, garante a legitimidade das decisões coletivas.

Os entrevistados ressaltaram que o CMI não consegue realizar o controle social da formulação das políticas públicas voltadas à pessoa idosa. Isso ocorre principalmente pelo fato de que há um processo de gestão que não abrange as características como a 
prioridade do interesse coletivo, o protagonismo da sociedade civil, a comunicação dialógica, e um processo de decisão descentralizado, inclusivo e participativo, que são características da gestão social (CANÇADO; TENÓRIO; PEREIRA, 2011). O controle social exercido pelo CMI é limitado pela fiscalização da implementação das políticas dos órgãos governamentais e pela fiscalização da prestação de serviços das instituições não governamentais.

Por meio da análise dos modelos de administração pública, dos modelos de coprodução do serviço público, foi possível identificar que na relação entre a administração pública municipal e o CMI e a comunidade há a predominância das características, relacionadas no escopo teórico, do modo de gestão estratégica. Nesse sentido, fica perceptível que o controle social da comunidade sobre a administração pública é limitado, não possuindo as características relacionadas à gestão social. À vista disso, com o predomínio das características da gestão estratégica, prepondera, também, o controle social da administração pública em relação à comunidade. A descrição dos dados da pesquisa demonstra que o CMI realiza um controle social acerca da execução de algumas políticas públicas, tanto produzidas pela administração pública quanto pelas organizações não governamentais, há características do controle social compartilhado entre a comunidade e a administração pública.

\section{Considerações Finais}

Esse estudo se propôs a identificar características do controle social no CMI por meio do diálogo entre as principais características que envolvem os modelos de administração pública, os modelos de coprodução dos serviços públicos e os modos de gestão estratégica e social, ambos como escopo teórico e prático para o controle social. Essa proposta fornece ao desenvolvimento científico da gestão social uma perspectiva diferente de analisar o processo de controle social. Por consequência, a partir da análise das entrevistas realizadas, da observação não participante e da análise documental foi possível fazer uma análise crítica-reflexiva, na qual, buscou-se fazer um confronto entre os pressupostos teóricos elucidados e a realidade observada no CMI.

Na relação entre a administração pública municipal e o CMI, está claro que há um processo de gestão que se aproxima da gestão estratégica, bem como das características da velha administração pública. O processo de gestão das políticas públicas relacionadas à pessoa idosa é centralizado na administração pública, com pouca participação do CMI e da comunidade. Logo, vê-se que não há prioridade ao interesse público por meio do controle social realizado pela comunidade em relação à administração pública, mas sim um controle social exercido pela administração pública sobre a comunidade. Contudo, quando o CMI, em parceria com o Ministério Público, realiza o controle social de algumas políticas públicas produzidas tanto pela administração pública municipal quanto pelas organizações não governamentais, há características do controle social compartilhado entre a comunidade e a administração pública.

Na gestão do CMI é possível identificar algumas características que se aproximam da gestão social. O processo de discussão e deliberação aberto para participação de forma igualitária entre os conselheiros e o incentivo à participação dos conselheiros e da comunidade são exemplos dessas características. No entanto, o CMI possui alguns desafios a superar para que a sua gestão vá em direção a um processo de gestão mais participativo, inclusivo e pautado na legitimidade das ações, características essas, da gestão social. Entre os desafios destaca-se a necessidade de uma comunicação mais efetiva entre conselho e comunidade, buscando divulgar as suas atribuições e atividades. Essa prática teria o intuito de proporcionar maior participação da comunidade no processo de discussão das questões relacionadas à pessoa idosa, superando a representatividade da mesma pelos conselheiros representantes das organizações não governamentais. Outro desafio consiste em buscar uma maior participação dos conselheiros no processo de discussão e deliberação.

Por fim, cabe ressaltar que, se houver um processo de maior integração dos conselheiros e da comunidade acerca da discussão e da deliberação das políticas públicas do idoso, o CMI terá uma maior representatividade perante a administração pública municipal. Isso impulsionará o controle social da formulação e implementação das políticas públicas, uma vez que a integração dos sujeitos promove, entre eles, um monitoramento coletivo e a busca da legitimidade das decisões coletivas. 


\section{RefERÊNCIAS}

ARENDT, H. A Condição humana. 11. ed. rev. Tradução Roberto Raposo, Revisão Técnica, Adriano Correia. Rio de Janeiro: Forense Universitária, 2014.

ARNSTEIN, S. R. A Ladder Of Citizen Participation. Journal of the American Institute of Planners, Routledge, v. 35, n. 4, p. 216-224, 1969.

ARISTÓTELES. Política. São Paulo: Martin Claret, 2007.

BÓBBIO, N. Estado, Governo, Sociedade: para uma teoria geral da política. 14. ed. São Paulo: Paz e Terra, 2007.

BOULlOSA, R. de F; SCHOMMER, P. C. Limites da natureza da inovação ou qual o futuro da Gestão Social? In: ENCONTRO DA ASSOCIAÇÃO NACIONAL DE PÓSGRADUAÇÃO E PESQUISA EM ADMINISTRAÇÃO, 32, 2008, Rio de Janeiro. Anais..., Rio de Janeiro: ANPAD, 2008. 1 CD-ROM.

CANÇADO, A. C.; PEREIRA, J. R.; TENÓRIO, F. G; Gestão Social: reflexões teóricas e conceituais. Cad. EBAPE. BR, Rio de Janeiro, v. 9, n. 3, p. 681-703, 2011.

CASTELLS, M. Redes de indignação e esperança: movimentos sociais na era da internet. Rio de Janeiro: Jorge Zahar Editor Ltda., 2013.

DAGNINO, E. Sociedade Civil, Participação e Cidadania: de que estamos falando? In: MATO, Daniel (Org.).

Politicas de ciudadania y sociedade civil em tiempos de globalización. Caracas: FACES, 2004. p. 95-110.

DAHL, R. Poliarquia: participação e oposição. São Paulo: Edusp, 2005.

DEMO, P. Pobreza da Pobreza. Petrópolis: Editora Vozes, 2003.

DENHARDT, R. B.; DENHARDT, J. V. The New Public Service: serving, not steering. New York: M. E. Sharpe, 2011.

ETZIONI, A. Concepções alternativas de accoutability: o exemplo da gestão da saúde. In: HEIDMANN, F. G.; SALM, J. F. Políticas Públicas e Desenvolvimento: bases epistemológicas e modelos de análise. 3. ed. Brasília, DF: Editora Universidade de Brasília, 2014. p. 41-70.
FADUL, É. M. C.; DE AGUIAR MAC-ALLISTER DA SILVA, M.; PINTO DA SILVA, L. Ensaiando interpretações e estratégias para o campo da administração pública no Brasil. Revista de Administração Pública, Rio de Janeiro, v. 46, n. 6, p. 1.437-1.458, 2012.

GODOY, A. S. Introdução à pesquisa qualitativa e suas possibilidades. Revista de Administração de Empresas, São Paulo, v. 35, n. 2, p. 57-63, março-abril, 1995.

GODOY, A. S. Estudo de Caso Qualitativo. In: GODOI, C. K.; BANDEIRA-DE-MELLO, R.; SILVA, A. B. da. Pesquisa Qualitativa em estudos organizacionais: paradigmas, estratégias e métodos. São Paulo: Saraiva, 2006. Cap. 4. p. 115-146.

GOHN, M. da G. Conselhos gestores e participação sociopolítica. 4. ed. São Paulo: Cortez, 2011.

\section{GOULART, M. S. B. Participação e accountability} no controle social do orçamento público: o caso do conselho de desenvolvimento regional de Itajaí. 2011. 226 p. Tese (Doutorado) - Escola de Administração da Universidade Federal da Bahia, Bahia, 2011.

GRUPPI, E. Vícios privados, benefícios públicos? A ética na riqueza das nações. São Paulo: Companhia das Letras, 2007.

HABERMAS, J. Direito e Democracia: entre facticidade e validade. 2. ed. Rio de Janeiro: Tempo Brasileiro, 2003.

HEIDEMANN, F. G. Do sonho do progresso às políticas de desenvolvimento. In: HEIDMANN, F. G.; SALM,

J. F. Políticas Públicas e Desenvolvimento: bases epistemológicas e modelos de análise. 3. ed. Brasília, DF: Editora Universidade de Brasília, 2014. p. 41-70.

HIRSCHMAN, Albert O. As Paixões e os interesses. Rio de Janeiro: Record, 2002.

KOPPELL, J. G .S. Pathologies of Accountability: ICANN and chaleenge of "multiple accountabilities disorder".

Public Administration Review, [S.1.], v. 65, n. 1, p. 3-26, 2005.

MINAYO, M. C. de S. (Org.). Pesquisa social: teoria, método e criatividade. Petrópolis, RJ: Vozes, 1994.

OLIVEIRA, M. M. de. Como fazer pesquisa qualitativa. Petrópolis, RJ: Vozes, 2007. 
PAES DE PAULA, A. P. Por uma nova gestão pública. São Paulo: FGV, 2005.

PATEMAN, C. Participação e teoria democrática. Rio de Janeiro: Paz e Terra, 1992.

PIMENTEL, M. P. C.; PIMENTEL, T. D. Gestão social: perspectivas, princípios e (de)limitações. In: VI ENCONTRO DE ESTUDOS ORGANIZACIONAIS - EnEO, n. 6, 2010, Florianópolis, Brasil, 23 a 24 de maio de 2010. Anais... Florianópolis: ANPAD, 2010. Disponível em: < http://www.anpad.org.br/admin/pdf/ eneo418.pdf $>$. Acesso em: 14 out. 2014.

\section{RAMOS, A. G. Administração e contexto brasileiro.} Rio de Janeiro: Fundação Getúlio Vargas, 1983.

RAMOS, A. G. A Modernização em nova perspectiva: em busca do modelo de possibilidade. In: HEIDMANN, F. G.; SALM, J. F. Políticas públicas e desenvolvimento: bases epistemológicas e modelos de análise. 3. ed. Brasília, DF: Editora Universidade de Brasília, 2014. p. 41-70.

RAMOS, A. G. A Nova ciência das organizações: uma reconceitualização da riqueza das nações. Rio de Janeiro: Fundação Getúlio Vargas, 1981.

RAMOS, A. G. A Redução sociológica. 3. ed. Rio de Janeiro: Editora da Universidade Federal do Rio de Janeiro, 1996.

ROBERTS, N. Public deliberation in an age of direct citizen participation. The American Review of Public Administration, [S.l.], v. 34, n. 4, p. 315-353, 2004.

SALM, J. F. A base epistemológica da ação administrativa nas organizações substantivas e a formação do gestor social. In: ENCONTRO NACIONAL DE PESQUISADORES EM GESTÃO SOCIAL, 4, 2010, Lavras, MG, Anais eletrônicos... Lavras: ENAPEGS, 2010. Disponível em: <http://anaisenapegs.com. br/2010 > . Acesso em: 20 out. 2014.

SALM, J. F. Coprodução de bens e serviços públicos. In: BOULlOSA, Rosana de Freitas (Org.). Dicionário para a formação em gestão social. Salvador: CIAGS/UFBA, 2014. p. 42-44.
SALM, J. F; MENEGASSO, M. E. Proposta de modelos para a coprodução do bem público a partir das tipologias de participação. In: ENCONTRO CIENTÍFICO DE ADMINISTRAÇÃO DA ASSOCIAÇÃO NACIONAL DE PÓS-GRADUAÇÃO E PESQUISA EM ADMINISTRAÇÃO, 24, 2010, Rio de Janeiro, Anais... Rio de Janeiro: ANPAD, 2010. CD-ROM.

SANTOS, B. de S. Um discurso sobre as ciências. 7. ed. São Paulo: Cortez Editora, 2010.

TENÓRIO, F. G. (Re)visitando o conceito de gestão social. Desenvolvimento em Questão, Ijuí, v. 3, n. 5, p.101-124, jan. 2005.

TENÓRIO, F. G. Tem razão a gestão social? In: COLÓQUIO INTERNACIONAL DE ESPISTEMOLOGIA E SOCIOLOGIA DA CIÊNCIA DA ADMINISTRAÇÃO, 3, 2013, Florianópolis. Anais... Florianópolis: Colóquio, 2013. p. 1-17. Disponível em: <http://www. coloquioepistemologia.com.br/anais2013/ANE103.pdf $>$. Acesso em: 10 out. 2014.

VERA, E. I.; LAVALLE, A. G. Arquitetura da participação e controles democráticos no Brasil e no México. Novos

Estudos - CEBRAP, [S.l.], n. 92, p. 105-121, 2012.

VERGARA, S. C. Projetos e relatórios de pesquisa em administração. 8. ed. São Paulo: Atlas, 2007.

VOEgelin, E. A Nova Ciência da Política. 2. ed. Brasília, DF: Editora Universidade de Brasília, 1952.

WEBER, M. Economia e Sociedade. Brasília, DF: Editora Universidade de Brasília, 2004. 